\title{
Correction to: Reinstatement and lectotypification of Uraria pulchra (Leguminosae-Papilionoideae)
}

\author{
Jahnabi Gogoi ${ }^{1,2} \&$ Tikam Singh Rana ${ }^{1,2}$ \\ Correction to: KEW BULLETIN \\ https: / /doi.org/10.1007/S12225-021-09978-9
}

In our recently published paper "Reinstatement and lectotypification of Uraria pulchra (LeguminosaePapilionoideae)" DOI 10.1007/S12225-021-09978-9, one minor detail is missing in the Acknowledgements section. The manuscript number provided by the ethics committee of CSIR-NBRI, that is required to be published in the paper was missing in the PDF proof and was published as such.

The original article has been corrected.
The online version of the original article can be found at https://doi.org/10.1007/s12225-021-09978-9

\section{Publisher's Note}

Springer Nature remains neutral with regard to jurisdictional claims in published maps and institutional affiliations.

\footnotetext{
Accepted for publication 16 December 2021. Published online 27 December 2021

1 Molecular Systematics Laboratory, Plant diversity, Systematics and Herbarium Division, CSIR-National Botanical Research Institute, Lucknow, 226001, India. e-mail: ranats@nbri.res.in

2 Academy of Scientific and Innovative Research (AcSIR), Ghaziabad, 201002, India.
} 